\title{
Pharmacokinetic Interaction Study of Ketamine and Rhynchophylline in Rat Plasma by Ultra-Performance Liquid Chromatography Tandem Mass Spectrometry
}

\author{
Lianguo Chen, ${ }^{1}$ Weiwei You, ${ }^{1}$ Dingwen Chen, ${ }^{1}$ Yuan Cai, ${ }^{1}$ Xianqin Wang $\left({ }^{2},{ }^{2}\right.$ \\ Congcong Wen $\mathbb{D}^{3},{ }^{3}$ and $B o W u\left(\mathbb{D}^{3}\right.$ \\ ${ }^{1}$ The Third Clinical Institute Affiliated to Wenzhou Medical University \& Wenzhou People's Hospital, Wenzhou 325000, China \\ ${ }^{2}$ Analytical and Testing Center, School of Pharmaceutical Sciences, Wenzhou Medical University, Wenzhou 325035, China \\ ${ }^{3}$ Laboratory Animal Centre, Wenzhou Medical University, Wenzhou, China
}

Correspondence should be addressed to Congcong Wen; bluce494949@163.com and Bo Wu; wubowzmu@163.com

Received 7 March 2018; Accepted 11 April 2018; Published 23 May 2018

Academic Editor: Gail B. Mahady

Copyright (c) 2018 Lianguo Chen et al. This is an open access article distributed under the Creative Commons Attribution License, which permits unrestricted use, distribution, and reproduction in any medium, provided the original work is properly cited.

Eighteen Sprague-Dawley rats were randomly divided into three groups: ketamine group, rhynchophylline group, and ketamine combined with rhynchophylline group $(n=6)$. The rats of two groups received a single intraperitoneal administration of $30 \mathrm{mg} / \mathrm{kg}$ ketamine and $30 \mathrm{mg} / \mathrm{kg}$ rhynchophylline, respectively, and the third group received combined intraperitoneal administration of $30 \mathrm{mg} / \mathrm{kg}$ ketamine and $30 \mathrm{mg} / \mathrm{kg}$ rhynchophylline together. After blood sampling at different time points and processing, the concentrations of ketamine and rhynchophylline in rat plasma were determined by the established ultra-performance liquid chromatography tandem mass spectrometry (UPLC-MS/MS) method. Chromatographic separation was achieved using a UPLC BEH C18 column $(2.1 \mathrm{~mm} \times 50 \mathrm{~mm}, 1.7 \mu \mathrm{m})$ with carbamazepine as an internal standard (IS). The initial mobile phase consisted of acetonitrile and water (containing $0.1 \%$ formic acid) with gradient elution. Multiple reaction monitoring (MRM) modes of $m / z$ $238.1 \rightarrow 179.1$ for ketamine, $m / z 385.3 \rightarrow 159.8$ for rhynchophylline, and $m / z 237.3 \rightarrow 194.3$ for carbamazepine (IS) were utilized to conduct quantitative analysis. Calibration curve of ketamine and rhynchophylline in rat plasma demonstrated good linearity in the range of 1-1000 ng/mL ( $\mathrm{r}>0.995)$, and the lower limit of quantification (LLOQ) was $1 \mathrm{ng} / \mathrm{mL}$. Moreover, the intra- and interday precision relative standard deviation (RSD) of ketamine and rhynchophylline were less than $11 \%$ and $14 \%$, respectively. This sensitive, rapid, and selective UPLC-MS/MS method was successfully applied to pharmacokinetic interaction study of ketamine and rhynchophylline after intraperitoneal administration. The results showed that there may be a reciprocal inhibition between ketamine and rhynchophylline.

\section{Introduction}

Ketamine is clinically used for surgical anesthesia [1,2]. Commonly known as "K powder", ketamine was epidemically abused in the United States in the early 70s of last century $[3,4]$. With the widespread abuse of "party drug" worldwide since the 1990s, the abuse of ketamine quickly spread to the Asian region or even mainland China [5, 6]. Ketamine was often abused in entertainment venues, making it one of the relatively popular new drugs currently $[7,8]$.

Traditional Chinese medicines such as Gastrodia Elata and Uncaria which can suppress hyperactive liver for calming endogenous wind, together with drugs which can warm kidney and activate yang and disperse stagnated liver qi for relieving qi stagnation, are used in clinical treatment with a good therapeutic effect $[9,10]$. Therefore, as a common traditional Chinese medicine in modern detoxification compound, Uncaria is frequently used as the main drug in detoxification preparations, such as Kangfuxin capsule, composite Dongyuan Gao, Shutongan capsule, and other preparations. Clinical studies have confirmed that these traditional Chinese medicine compounds are effective in controlling the withdrawal symptoms, relieving mental dependence, and 


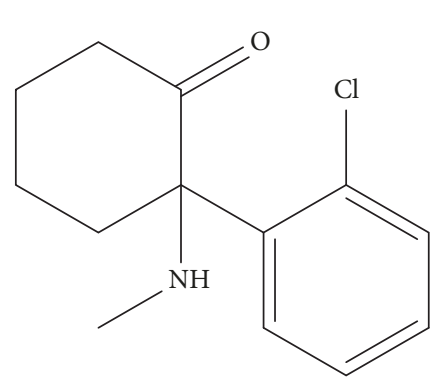

(a)

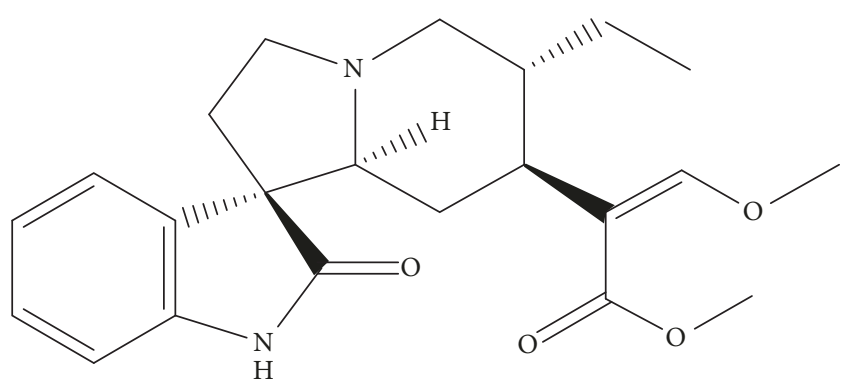

(b)

FIgURE 1: Molecular structure of ketamine (a) and rhynchophylline (b).

reducing relapse [11, 12]. Moreover, they are safe and effective, with no obvious side effects.

Consequently, in the present study, we established a UPLC-MS/MS method for the quantification of ketamine and rhynchophylline in rat plasma. Meanwhile, we investigated the pharmacokinetic interaction of them to explore the antiketamine addiction mechanism of rhynchophylline.

\section{Materials and Methods}

2.1. Chemicals and Reagents. Ketamine (purity $>98 \%$, Figure 1(a)), rhynchophylline (purity $>98 \%$, Figure $1(\mathrm{~b})$ ), and carbamazepine (IS, purity > 98\%) were purchased from Chinese Biopharmaceutical Institute (Beijing, China). High performance liquid chromatography-grade acetonitrile and methanol were purchased from Merck Company (Darmstadt, Germany). Ultra-pure water was prepared by a Milli-Q purification system (Millipore Bedford, MA). Sprague-Dawley rats (200-220 g) were purchased from Laboratory Animal Centre of Wenzhou Medical University [2].

2.2. Instrumentation and Conditions. A UPLC-MS/MS system with ACQUITY I-Class UPLC and a XEVO TQS-micro triple quadrupole mass spectrometer (Waters Corp., Milford, MA, USA) and Masslynx 4.1 software (Waters Corp.) was used for data acquisition and instrument control. Chromatographic separation was achieved using a UPLC BEH C18 column $(2.1 \mathrm{~mm} \times 50 \mathrm{~mm}, 1.7 \mu \mathrm{m})$ (Waters Corp., Milford, MA, USA) maintained at $40^{\circ} \mathrm{C}$. The temperature of UPLCMS sampling chamber was maintained at $10^{\circ} \mathrm{C}$. The initial mobile phase consisted of acetonitrile and water (containing $0.1 \%$ formic acid) with gradient elution at a flow rate of $0.4 \mathrm{~mL} / \mathrm{min}$. Elution was in a linear gradient, where the acetonitrile content was maintained at $10 \%$ between 0 and 0.2 min, increased to $80 \%$ between 0.2 and $1.5 \mathrm{~min}$, maintained at $80 \%$ between 1.5 and $2.0 \mathrm{~min}$, then decreased to $10 \%$ between 2.0 and $2.5 \mathrm{~min}$, and maintained at $10 \%$ between 2.5 and 4.0 $\mathrm{min}$. The total run time of the analytes was $4 \mathrm{~min}$.

Nitrogen was used as the desolvation gas $(1000 \mathrm{~L} / \mathrm{h})$ and cone gas $(50 \mathrm{~L} / \mathrm{h})$. Ion monitoring conditions were defined as capillary voltage of $1.5 \mathrm{kV}$, source temperature of $150^{\circ} \mathrm{C}$, and desolvation temperature of $500^{\circ} \mathrm{C}$ [13]. MRM modes of $\mathrm{m} / \mathrm{z} 238.1 \rightarrow 179.0$ for ketamine, $\mathrm{m} / \mathrm{z} 385.2 \rightarrow 160.1$ for rhynchophylline, and $\mathrm{m} / \mathrm{z} 237.1 \rightarrow 194.0$ for carbamazepine (IS) were utilized to conduct quantitative analysis, Figure 2.
2.3. Quality Control Samples Preparation. The stock solutions of ketamine $(1.0 \mathrm{mg} / \mathrm{mL})$, rhynchophylline $(1.0 \mathrm{mg} / \mathrm{mL})$, and carbamazepine (IS) were prepared in methanol-water. The working standard solution of IS was prepared from the IS stock solution by dilution with methanol; working solutions for calibration and controls were prepared from stock solutions similarly, using methanol diluent. All of the solutions were stored at $4^{\circ} \mathrm{C}$ and were brought to room temperature before use [14].

2.4. Calibration Standards Preparation. Ketamine and rhynchophylline calibration standards were prepared by spiking blank rat plasma with appropriate amounts of the working solutions [15]. Calibration plots were offset to range between 1 and $1000 \mathrm{ng} / \mathrm{mL}$ for ketamine or rhynchophylline in rat plasma at 1, 5, 20, 50, 100, 200, 500, and $1000 \mathrm{ng} / \mathrm{mL}$. Quality control (QC) samples were prepared in the same manner as the calibration standards, in three different plasma concentration levels (2, 90, and $900 \mathrm{ng} / \mathrm{mL}$ ).

2.5. Sample Preparation. One hundred microliter of plasma sample was mixed with $200 \mu \mathrm{L}$ of acetonitrile containing 50 $\mathrm{ng} / \mathrm{mL}$ carbamazepine (IS) in a $1.5-\mathrm{mL}$ centrifuge tube and then extracted by vortexing for $1.0 \mathrm{~min}$ to deproteinize the endogenous protein. After centrifugation at $14900 \mathrm{~g}$ for 10 min at $4^{\circ} \mathrm{C}, 100 \mu \mathrm{L}$ of the supernatant was collected into the inner lining-pipe of a sample vial. Two microliters of the supernatant was injected into the UPLC-MS/MS system for analysis.

2.6. Pharmacokinetic Study. Eighteen Sprague-Dawley rats (200-220 g) were randomly divided into three groups: ketamine group, rhynchophylline group, and ketamine combined with rhynchophylline group $(n=6)$ [6]. Ketamine and rhynchophylline were dissolved in 2\% dimethyl sulfoxide (DMSO). Two groups received a single intraperitoneal (ip) administration (30 mg/kg ketamine and $30 \mathrm{mg} / \mathrm{kg}$ rhynchophylline, respectively), and the third group received combined intraperitoneal (ip) administration of $30 \mathrm{mg} / \mathrm{kg}$ ketamine and $30 \mathrm{mg} / \mathrm{kg}$ rhynchophylline together. Blood samples $(0.3 \mathrm{~mL})$ from the tail vein were collected into 1.5 $\mathrm{mL}$ heparinized polypropylene tubes at $0.25,1,3,6,8,10$, and $24 \mathrm{~h}$ after intraperitoneal administration. The samples were immediately centrifuged at $13000 \mathrm{rpm}$ for $10 \mathrm{~min}$ at $4^{\circ} \mathrm{C}$. Then 


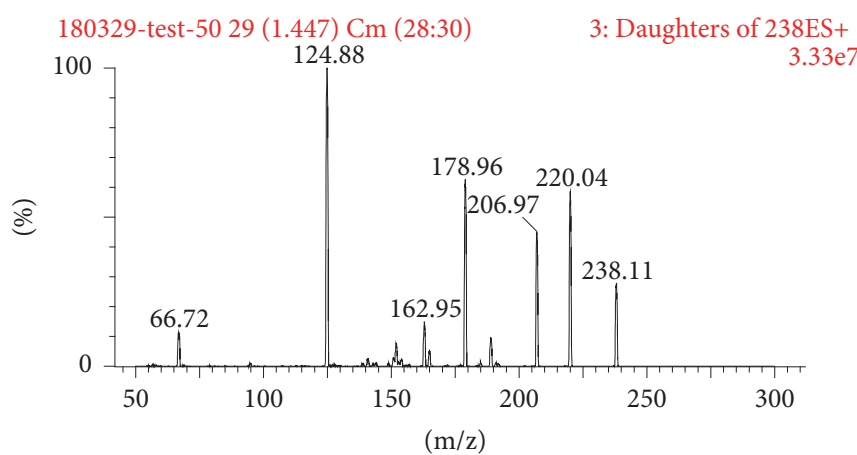

(a)

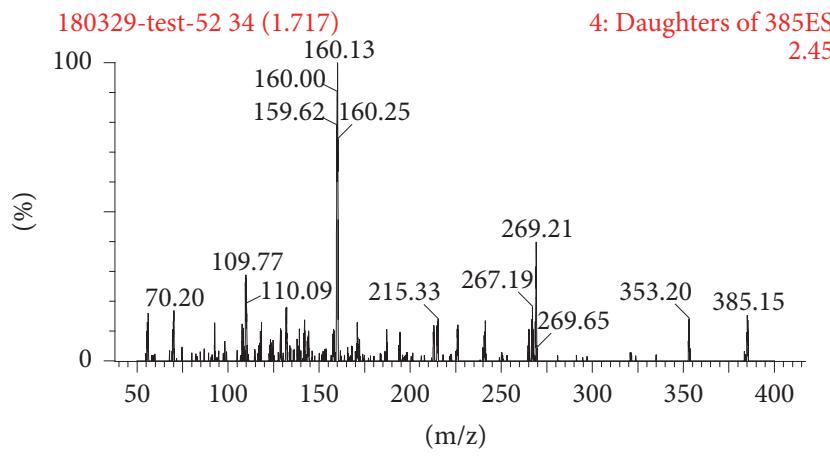

(b)

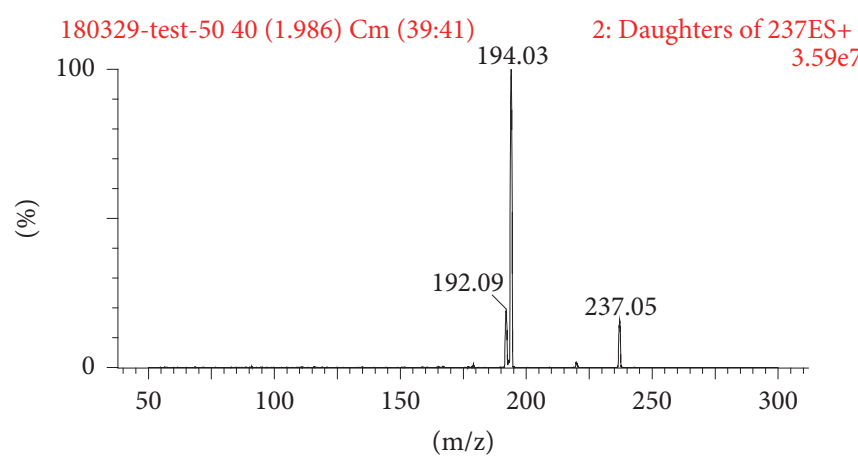

(c)

Figure 2: Mass spectra of ketamine (a), rhynchophylline, (b) and carbamazepine (IS, c).

the plasma was transferred to a new $1.5 \mathrm{~mL}$ tube and stored at $-20^{\circ} \mathrm{C}$ until analysis.

Plasma concentration versus time data for each rat was analyzed by DAS (Drug and Statistics) software (version 2.0, China Pharmaceutical University). The area under the plasma concentration-time curve (AUC), mean residence time (MRT), plasma clearance (CL), apparent volume of distribution $(\mathrm{V})$, maximum plasma concentration $\left(\mathrm{C}_{\max }\right)$, and half-life $\left(t_{1 / 2}\right)$ were estimated using noncompartmental calculations performed with DAS software [15].

\section{Results}

3.1. UPLC-MS/MS Method Verification. Typical UPLC-MS/ MS chromatograms of blank plasma, blank plasma spiked with ketamine, rhynchophylline, and carbamazepine (IS), and plasma samples collected from the caudal vein of rats were shown in Figure 3. No interference of visible impurity and endogenous substances was observed, indicating that the analyte of interest and IS were efficiently separated by the optimized gradient elution procedure.

Calibration curve of ketamine and rhynchophylline in rat plasma demonstrated good linearity in the range of 1$1000 \mathrm{ng} / \mathrm{mL}$. Typical regression equations were as follows: $\mathrm{Y}_{1}=0.00041 \mathrm{X}_{1}+0.00094, \mathrm{r}=0.9996 ; \mathrm{Y}_{2}=0.00454 \mathrm{X}_{2}$ $0.00928, r=0.9975$. $Y_{1}$ represents the ratios of peak intensity of ketamine to the internal standard, and $\mathrm{X}_{1}$ represents the concentration of ketamine in plasma; $\mathrm{Y}_{2}$ represents the ratios of peak intensity of rhynchophylline to the internal standard, and $\mathrm{X}_{2}$ represents the concentration of rhynchophylline in plasma. The LLOQ of ketamine and rhynchophylline in rat plasma was $1 \mathrm{ng} / \mathrm{mL}$.

As shown in Table 1, the intra- and interday precision RSD at three concentration levels of ketamine were all less than 


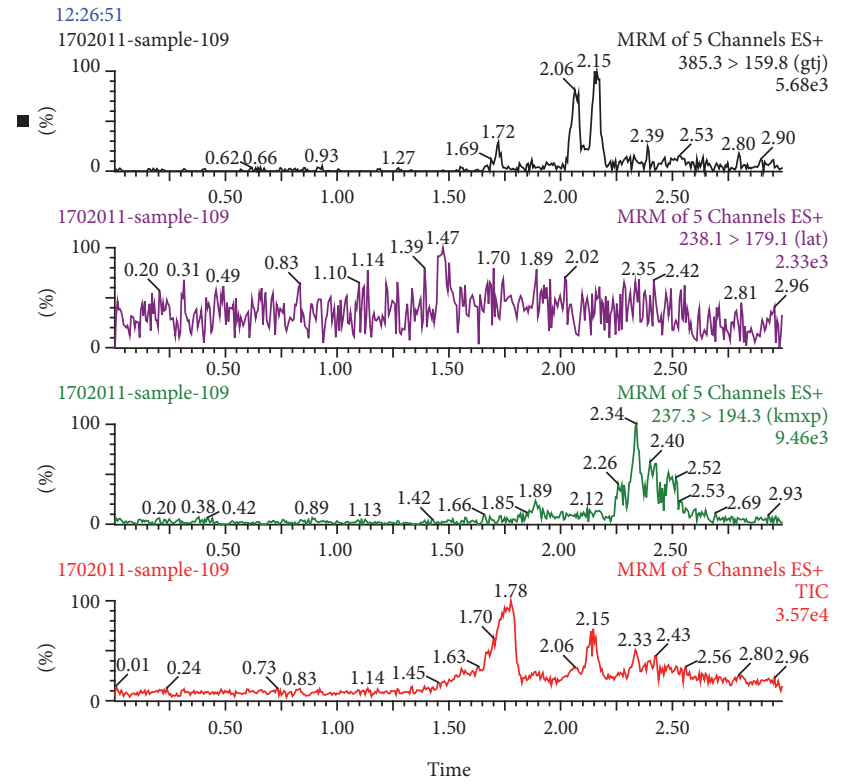

(a)

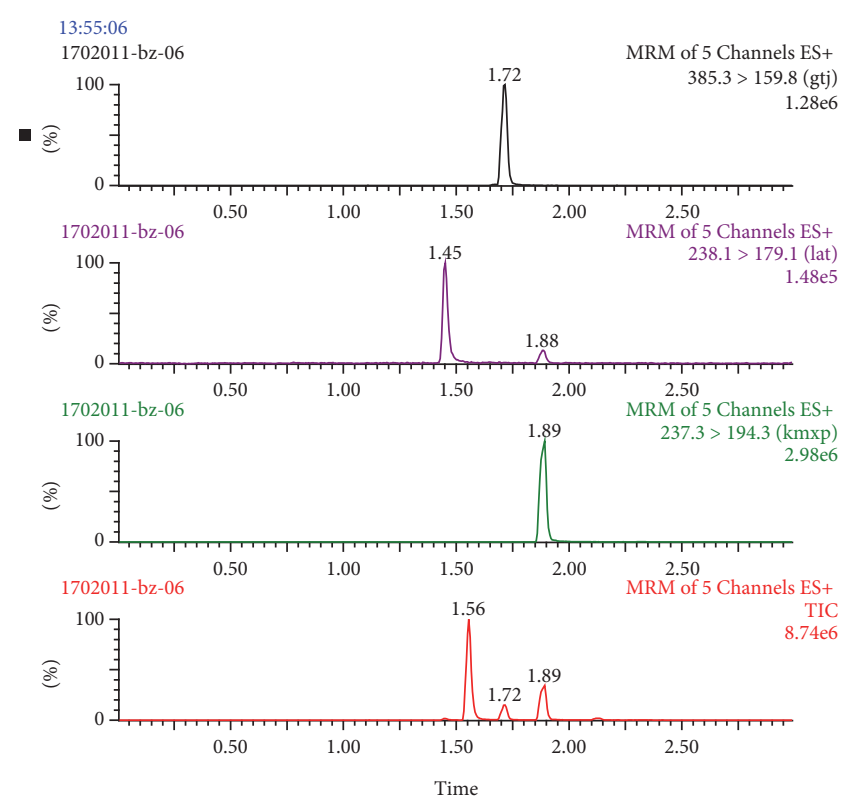

(b)

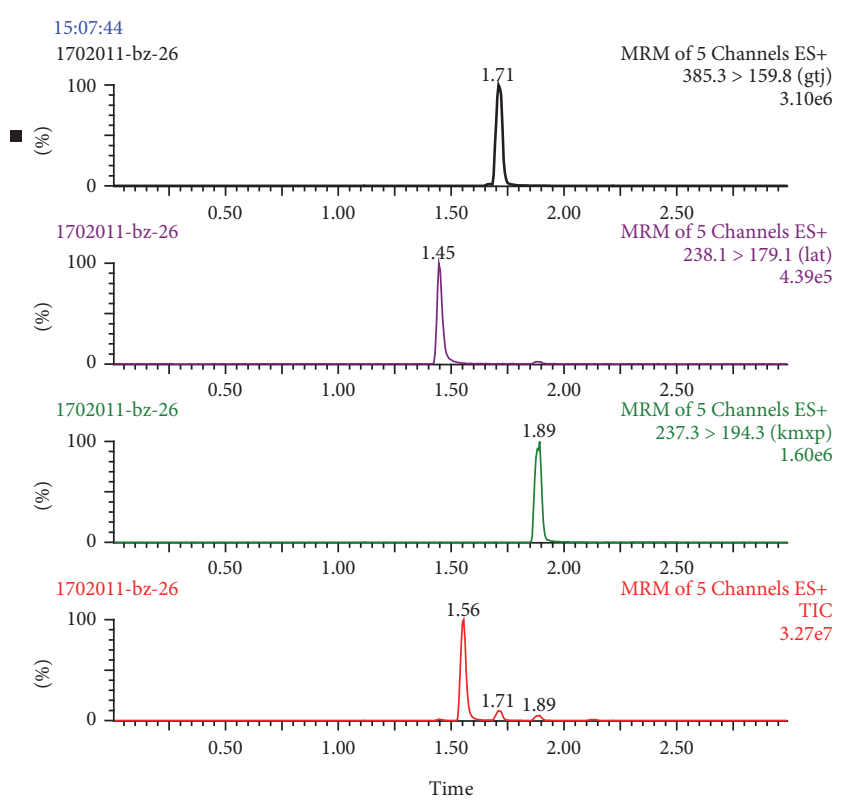

(c)

FIGURE 3: Representative UPLC-MS/MS chromatograms: (a) blank plasma; (b) blank plasma spiked with ketamine, rhynchophylline, and carbamazepine (IS); (c) a rat plasma sample $2 \mathrm{~h}$ after intraperitoneal administration.

TABle 1: Precision, accuracy, and recovery of ketamine in rat plasma $(n=6)$.

\begin{tabular}{|c|c|c|c|c|c|c|}
\hline \multirow{2}{*}{ Concentration $(\mathrm{ng} / \mathrm{mL})$} & \multicolumn{2}{|c|}{ Precision (RSD\%) } & \multicolumn{2}{|c|}{ Accuracy (\%) } & \multirow{2}{*}{ Recovery (\%) } & \multirow{2}{*}{ Matrix effect (\%) } \\
\hline & Intraday & Interday & Intraday & Interday & & \\
\hline 2 & 10.0 & 10.4 & 99.1 & 95.4 & 72.6 & 108.7 \\
\hline 90 & 7.9 & 5.6 & 94.3 & 111.8 & 73.3 & 103.8 \\
\hline 900 & 6.0 & 7.9 & 108.7 & 94.8 & 74.9 & 104.3 \\
\hline
\end{tabular}


TABLE 2: Precision, accuracy, and recovery of rhynchophylline in rat plasma $(n=6)$.

\begin{tabular}{|c|c|c|c|c|c|c|}
\hline \multirow{2}{*}{ Concentration $(\mathrm{ng} / \mathrm{mL})$} & \multicolumn{2}{|c|}{ Precision (RSD\%) } & \multicolumn{2}{|c|}{ Accuracy (\%) } & \multirow{2}{*}{ Recovery (\%) } & \multirow{2}{*}{ Matrix effect (\%) } \\
\hline & Intraday & Interday & Intraday & Interday & & \\
\hline 2 & 12.5 & 13.3 & 110.2 & 90.4 & 68.0 & 102.7 \\
\hline 180 & 9.7 & 7.9 & 93.3 & 103.6 & 66.2 & 100.1 \\
\hline 900 & 4.7 & 11.2 & 100.4 & 104.2 & 69.9 & 98.8 \\
\hline
\end{tabular}

TABLE 3: Primary pharmacokinetic parameters after intraperitoneal administration of ketamine in rats $(n=6)$.

\begin{tabular}{lccc}
\hline Parameters & Unit & Ketamine & Ketamine + rhynchophylline \\
\hline $\mathrm{AUC}_{(0-\mathrm{t})}$ & $\mathrm{ng} / \mathrm{mL} * \mathrm{~h}$ & $1080.4 \pm 156.6$ & $4085.7 \pm 2784.8^{*}$ \\
$\mathrm{AUC}_{(0-\infty)}$ & $\mathrm{ng} / \mathrm{mL} * \mathrm{~h}$ & $1083.4 \pm 158.7$ & $4086.7 \pm 2784.3^{*}$ \\
$\mathrm{MRT}_{(0-\mathrm{t})}$ & $\mathrm{h}$ & $1.4 \pm 0.3$ & $1.0 \pm 0.3$ \\
$\mathrm{MRT}_{(0-\infty)}$ & $\mathrm{h}$ & $1.4 \pm 0.3$ & $1.1 \pm 0.3$ \\
$\mathrm{t}_{1 / 2}$ & $\mathrm{~h}$ & $5.4 \pm 2.6$ & $2.4 \pm 1.5$ \\
$\mathrm{CL}$ & $\mathrm{L} / \mathrm{h} / \mathrm{kg}$ & $28.1 \pm 3.7$ & $10.4 \pm 5.6^{* *}$ \\
$\mathrm{~V}$ & $\mathrm{~L} / \mathrm{kg}$ & $208.1 \pm 84.3$ & $35.2 \pm 28.3^{* *}$ \\
$\mathrm{C}_{\max }$ & $\mathrm{ng} / \mathrm{mL}$ & $779.5 \pm 212.6$ & $3275.7 \pm 2357.1^{*}$ \\
\hline
\end{tabular}

Compared to ketamine group, ${ }^{*} P<0.05,{ }^{* *} P<0.01$.

$11 \%$ and the accuracy was in the range of $94.3 \%$ to $111.8 \%$. The mean recovery was higher than $72.6 \%$ and the matrix effect was between $103.8 \%$ and $108.7 \%$. It is known from Table 2 that the intra- and interday precision RSD of rhynchophylline were less than $14 \%$ and the accuracy was in the range of $93.3 \%$ to $110.2 \%$. The mean recovery was higher than $66.2 \%$ and the matrix effect was between $98.8 \%$ and $102.7 \%$. These results demonstrated that the precision, accuracy, recovery, and matrix effect of the established UPLC-MS/MS method were all conformed to the pharmacokinetic requirements of ketamine and rhynchophylline.

3.2. Pharmacokinetic Study. The mean plasma concentration-time curve of ketamine is shown in Figure 4; the mean plasma concentration-time curve of rhynchophylline is shown in Figure 5; primary pharmacokinetic parameters which are based on noncompartmental model analysis are summarized in Tables 3 and 4.

\section{Discussion}

In the present study, a sensitive, rapid, and selective UPLCMS/MS method for the quantitation of ketamine and rhynchophylline in rat plasma was established, utilizing $100 \mu \mathrm{L}$ of plasma with an LLOQ of $1 \mathrm{ng} / \mathrm{mL}$ and 4 min total run time. The UPLC-MS/MS method was successfully applied to pharmacokinetic interaction study of ketamine and rhynchophylline, which suggested that there may be a reciprocal inhibition between them.

The combination of various drugs is very common in clinical treatment and the interaction of drugs has drawn more and more attention. The drug metabolic interaction generated by the induction or inhibition of Chinese herbal medicine on hepatic drug-metabolizing enzymes (CYP450) is an important part and the most common cause of the interaction between Chinese and Western medicines [16].

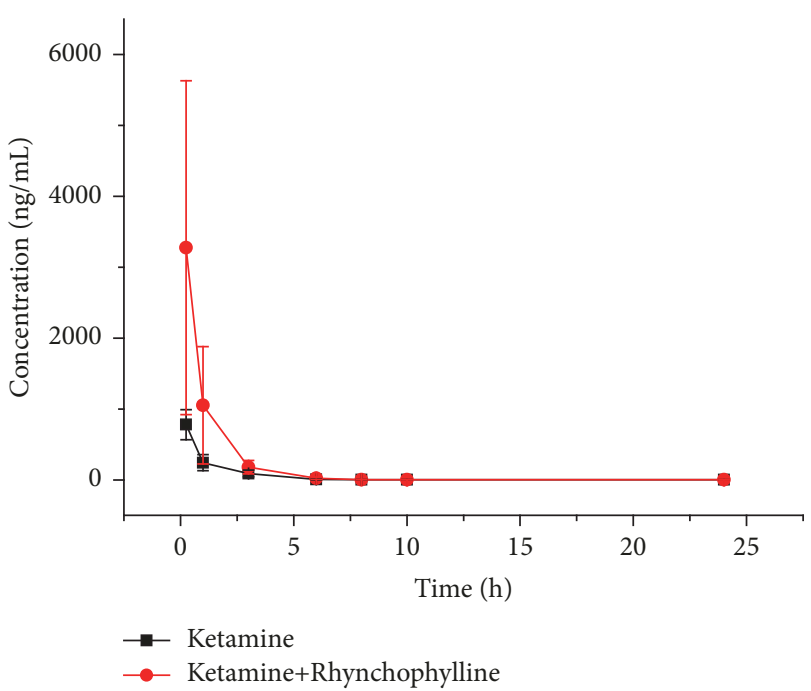

FIGURE 4: Mean plasma concentration-time curves of ketamine after intraperitoneal administration of a single $30 \mathrm{mg} / \mathrm{kg}$ ketamine and 30 $\mathrm{mg} / \mathrm{kg}$ ketamine combined with $30 \mathrm{mg} / \mathrm{kg}$ rhynchophylline in rats.

Rhynchophylline and ketamine are both noncompetitive antagonists of N-methyl-D-aspartic acid receptors (NMDA) and can be used to interfere with ketamine addiction when they are used together [17]. Therefore, it is of great significance to study the pharmacokinetic changes after the combined use of rhynchophylline and ketamine. At present, no relevant reports have been found yet.

Most interactions of herbal medicine and Western medicine mainly appeared by affecting the emergence of cytochrome P450, UDP-glucuronosyl transferase (UGT), or drug transport protein $[18,19]$. Herbal medicine can inhibit or induce these enzymes or protein to increase or decrease the medical concentration in blood, viscera, urine, or bile and 
TABLE 4: Primary pharmacokinetic parameters after intraperitoneal administration of rhynchophylline in rats $(n=6)$.

\begin{tabular}{lccc}
\hline Parameters & Unit & Rhynchophylline & Ketamine + rhynchophylline \\
\hline $\mathrm{AUC}_{(0-\mathrm{t})}$ & $\mathrm{ng} / \mathrm{mL} * \mathrm{~h}$ & $1090.9 \pm 710.8$ & $2620.0 \pm 1291.2^{*}$ \\
$\mathrm{AUC}_{(0-\infty)}$ & $\mathrm{ng} / \mathrm{mL} * \mathrm{~h}$ & $1094.8 \pm 715.1$ & $2650.3 \pm 1269.4^{*}$ \\
$\mathrm{MRT}_{(0-\mathrm{t})}$ & $\mathrm{h}$ & $2.9 \pm 0.7$ & $1.8 \pm 0.5^{*}$ \\
$\mathrm{MRT}_{(0-\infty)}$ & $\mathrm{h}$ & $2.9 \pm 0.8$ & $3.1 \pm 2.6$ \\
$\mathrm{t}_{1 / 2}$ & $\mathrm{~h}$ & $2.9 \pm 2.2$ & $11.5 \pm 19.1$ \\
$\mathrm{CL}$ & $\mathrm{L} / \mathrm{h} / \mathrm{kg}$ & $40.9 \pm 29.0$ & $13.3 \pm 5.1^{*}$ \\
$\mathrm{~V}$ & $\mathrm{~L} / \mathrm{kg}$ & $146.3 \pm 100.5$ & $264.0 \pm 473.0$ \\
$\mathrm{C}_{\max }$ & $\mathrm{ng} / \mathrm{mL}$ & $314.9 \pm 162.1$ & $1133.7 \pm 433.9^{* *}$ \\
\hline
\end{tabular}

Compared to ketamine group, ${ }^{*} P<0.05,{ }^{* *} P<0.01$.

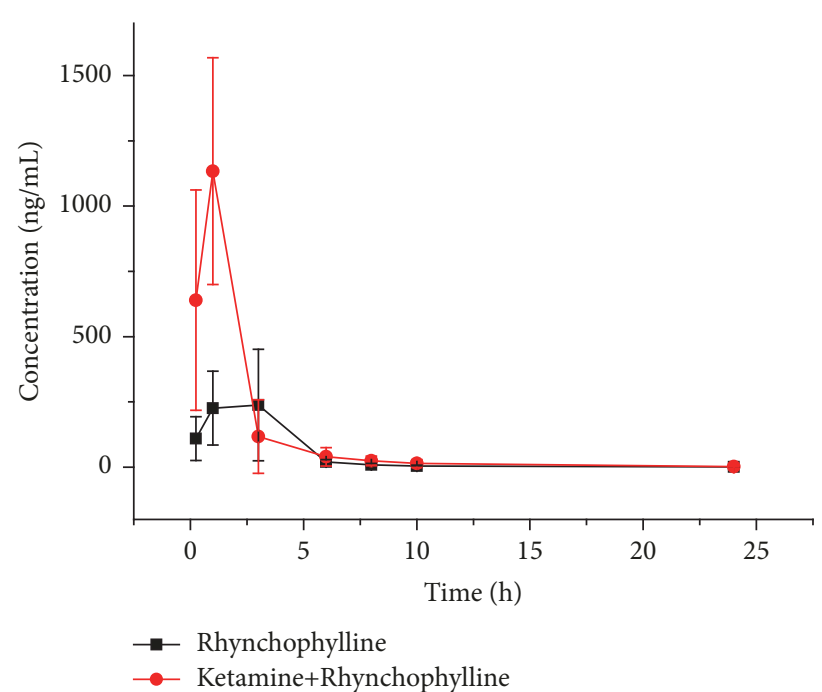

FIgURE 5: Mean plasma concentration-time curves of rhynchophylline after intraperitoneal administration of a single $30 \mathrm{mg} / \mathrm{kg}$ rhynchophylline and $30 \mathrm{mg} / \mathrm{kg}$ ketamine combined with $30 \mathrm{mg} / \mathrm{kg}$ rhynchophylline in rats.

proceed to cause the change of pharmacokinetic parameters and lead to ineffective treatment of the medicine or potential adverse reactions.

The results showed that primary pharmacokinetic parameter of ketamine such as $\mathrm{C}_{\max }$ was $779.5 \pm 212.6 \mathrm{ng} / \mathrm{mL}$, $\mathrm{AUC}_{(0-\infty)}$ was $1083.4 \pm 158.7 \mathrm{ng} / \mathrm{mL} * \mathrm{~h}, \mathrm{MRT}_{(0-\infty)}$ was $1.4 \pm$ $0.3 \mathrm{~h}, \mathrm{CL}$ was $28.1 \pm 3.7 \mathrm{~L} / \mathrm{h} / \mathrm{kg}, \mathrm{t}_{1 / 2}$ was $5.4 \pm 2.6 \mathrm{~h}$, and $\mathrm{V}$ was $208.1 \pm 84.3 \mathrm{~L} / \mathrm{kg}$. Compared with single ketamine group, there were significant differences of $\mathrm{C}_{\max }, \mathrm{AUC}, \mathrm{V}$, and $\mathrm{CL}_{\mathrm{z} / \mathrm{F}}$ after administration of ketamine combined with rhynchophylline. $\mathrm{C}_{\max }$ and AUC were increased 3.2 and 2.8 times, respectively, after combined use, suggesting that rhynchophylline may increase the absorption of ketamine, while V, CL, and $t_{1 / 2}$ were only $17.0 \%, 37.0 \%$, and $44.4 \%$, respectively, of those of single ketamine group, suggesting that the distribution and metabolism of ketamine were obviously decreased after being combined with rhynchophylline. The investigation of Hijazi Y et al. showed that the subtypes of CYP 450 (CYP2C9, CYP2B, and CYP3A) participated in $\mathrm{N}$-demethylation of ketamine in rats liver, and ketamine may interact with the aforesaid enzyme substrate in vivo
[20]. Therefore, rhynchophylline may theoretically induce CYP2B6, CYP3A4, and CYP2C9 to accelerate the metabolism of ketamine. However, it was inconsistent with our results, indicating that rhynchophylline mainly inhibited ketamine metabolism through other ways. The obvious medical interaction appeared by regulation of medical absorption, distribution, metabolism, and excretion with CYP450 as well as UDP-glucuronosyl transferase (UGT) and drug transport protein (OCT1, OCT2, OAT1, OAT3, OATP1B1, OATP1B3, P-gp, and BCRP) [19]. The binding rate of drug plasma protein was also the important factor to the interaction, especially to the approachable drug with plasma protein [21]. In addition, the constituent of Uncaria was complex; there were isorhynchophylline, corynoxeine, isocorynoxeine, corynantheine, corynoxein, isocorynoxeine, and so forth besides rhynchophylline [22, 23]. Therefore, the intervening results of Uncaria decoction on hepatic enzyme were not able to directly explain the effect of rhynchophylline on hepatic enzyme. There were no relevant reports on these influence factors, and further verification was needed on the interaction of rhynchophylline and ketamine. At present, although the relevant mechanism was not definite, attention should be given on the effect of increasing absorption and inhibiting metabolism of ketamine by rhynchophylline, because it may result in an unnecessary liver injury or other adverse reactions if the plasma concentration of ketamine was too high [24].

The results also showed that primary pharmacokinetic parameter of rhynchophylline such as $\mathrm{C}_{\max }$ was $314.9 \pm 162.1$ $\mathrm{ng} / \mathrm{mL}, \mathrm{AUC}_{(0-\infty)}$ was $1094.8 \pm 715.1 \mathrm{ng} / \mathrm{mL} * \mathrm{~h}, \mathrm{MRT}_{(0-\infty)}$ was $2.9 \pm 0.8 \mathrm{~h}$, CL was $40.9 \pm 29.0 \mathrm{~L} / \mathrm{h} / \mathrm{kg}, \mathrm{t}_{1 / 2}$ was $2.9 \pm 2.2 \mathrm{~h}$, and $\mathrm{V}$ was $146.3 \pm 100.5 \mathrm{~L} / \mathrm{kg}$. Compared with single rhynchophylline group, there were significant differences of $\mathrm{C}_{\max }$, AUC, and CL after administration of ketamine combined with rhynchophylline. $C_{\max }$ and AUC were increased 2.6 and 1.4 times, respectively, after combined use, suggesting that ketamine may increase the absorption of rhynchophylline, while CL was decreased by $67.4 \%$ and $t_{1 / 2}$ was extended by 3.0 times (no significant differences), suggesting that ketamine may induce the metabolism of rhynchophylline. Ketamine had always been considered as a hepatic enzyme inducer previously, but other research in vivo and in vitro showed that ketamine can inhibit the activity of CYP1A, CYP2A, CYP2B, CYP2C, CYP2D1, and CYP3A $[24,25]$. The result 
of this contradiction was probably caused by different time and frequency of administration. Repeated administration and time of ketamine were required to gain the induction effect on hepatic enzyme. However, rhynchophylline was mainly metabolized through the hydroxylation of CYP2D, CYP1A1/2, and CYP2C [26]. Therefore, single administration of ketamine may decrease the activity of CYP2D, CYP1A1/2, and CYP2C to inhibit the hydroxylation of rhynchophylline. This hypothesis is consistent with our result, and further elaboration was needed for the detailed reasons.

\section{Conclusion}

In the present study, we investigated the pharmacokinetic interaction of ketamine and rhynchophylline based on a newly established UPLC-MS/MS method, which showed that rhynchophylline can increase the absorption and inhibit the metabolism of ketamine; meanwhile ketamine can increase the absorption and induce the metabolism of rhynchophylline. Hepatic enzyme was not able to completely explain their interaction in vivo of rats, and there were no relevant reports of UDP-glucuronosyl transferase, drug transport protein, and binding rate of plasma protein on this result. Further researches still need to be conducted to study the relevant mechanism, and attention should be given on the results that may be caused by their interactions clinically.

\section{Data Availability}

The data used to support the findings of this study are available from the corresponding author upon request.

\section{Conflicts of Interest}

The authors declare that they have no conflicts of interest.

\section{Authors' Contributions}

Lianguo Chen and Weiwei You contributed equally to this work.

\section{Acknowledgments}

This study was supported by grants from the Zhejiang Province Public Welfare Application Research Experimental Animal project (2017C37104); National Natural Science Foundation of China (81701314); Science and Technology Committee of Shanghai Municipality, China (KF1707).

\section{References}

[1] B. Short, J. Fong, V. Galvez, W. Shelker, and C. K. Loo, "Sideeffects associated with ketamine use in depression: A systematic review," The Lancet Psychiatry, vol. 5, no. 1, pp. 65-78, 2018.

[2] M. Zhang, C. Wen, Y. Zhang et al., "Serum metabolomics in rats models of ketamine abuse by gas chromatography-mass spectrometry," Journal of Chromatography B, vol. 1006, pp. 99103, 2015.
[3] F. Fernández-Calderón, C. Vidal-Giné, J. López-Guerrero, and Ó. M. Lozano-Rojas, "Reliability, convergent and structural validity and cut-off score of the Severity of Dependence Scale for recreational ketamine users," Addictive Behaviors, vol. 60, pp. $1-7,2016$.

[4] W. Li, J. S. Ma, M. Zeng, X. B. Wang, X. Q. Wang, and L. F. Hu, "Determination of Ketamine in Rabbit Plasma by Gradient Elution Liquid Chromatography/Electrospray Mass Spectrometry," Latin American Journal of Pharmacy, vol. 30, no. 9, pp. 1849-1853, 2011.

[5] C. Wen, M. Zhang, Y. Zhang et al., "Brain metabolomics in rats after administration of ketamine," Biomedical Chromatography, vol. 30, no. 1, pp. 81-84, 2016.

[6] C. Wen, M. Zhang, J. Ma, L. Hu, X. Wang, and G. Lin, "Urine metabolomics in rats after administration of ketamine," Drug Design, Development and Therapy, vol. 9, pp. 717-722, 2015.

[7] H. Uosukainen, U. Tacke, and A. R. Winstock, "Self-reported prevalence of dependence of MDMA compared to cocaine, mephedrone and ketamine among a sample of recreational poly-drug users," International Journal of Drug Policy, vol. 26, no. 1, pp. 78-83, 2015.

[8] X. Q. Wang, Q. Q. Wang, Q. P. Hu et al., "Effect of Ethanol on Pharmacokinetics of Ketamine in Rat," Latin American Journal of Pharmacy, vol. 36, no. 7, pp. 1403-1407, 2017.

[9] K.-C. Yu, H.-T. Wei, Y.-H. Yeh, and C.-H. Hsu, "Traditional Chinese medicine-facilitated treatments may relieve anxiety symptoms during drug switching from methadone to buprenorphine/naloxone for treating opioid dependence," BMJ Case Reports, vol. 2017, Article ID 220815, 2017.

[10] F. Doosti, S. Dashti, S. M. Tabatabai, and H. Hosseinzadeh, "Traditional Chinese and Indian medicine in the treatment of opioid-dependence: a review," Avicenna Journal of Phytomedicine, vol. 3, no. 3, pp. 205-15, 2013.

[11] S. Tu, J. Gao, J. Liu et al., "Effects of jitai tablet, a traditional chinese medicine, on spontaneous withdrawal symptoms and modulation of dopaminergic functions in morphine-dependent rats," Phytotherapy Research, vol. 29, no. 5, pp. 687-694, 2015.

[12] J. Shi, G.-Z. Xu, T.-T. Liu et al., "A comparative clinical study of the effects of the traditional Chinese medicine Jinniu capsules and lofexidine on acute heroin withdrawal symptoms," American Journal of Drug and Alcohol Abuse, vol. 34, no. 6, pp. 792-800, 2008.

[13] S. Wang, H. Wu, P. Geng et al., "Pharmacokinetic study of dendrobine in rat plasma by ultra-performance liquid chromatography tandem mass spectrometry," Biomedical Chromatography, vol. 30, no. 7, pp. 1145-1149, 2016.

[14] S. Wang, H. Wu, X. Huang et al., "Determination of Nmethylcytisine in rat plasma by UPLC-MS/MS and its application to pharmacokinetic study," Journal of Chromatography B, vol. 990, pp. 118-124, 2015.

[15] C. Wen, J. Cai, C. Lin, J. Ma, and X. Wang, "Gradient elution liquid chromatography mass spectrometry determination of acetylcorynoline in rat plasma and its application to a pharmacokinetic study," Xenobiotica, vol. 44, no. 8, pp. 743-748, 2014.

[16] H.-J. Cho and I.-S. Yoon, "Pharmacokinetic interactions of herbs with cytochrome p450 and p-glycoprotein," EvidenceBased Complementary and Alternative Medicine, vol. 2015, Article ID 736431, 10 pages, 2015.

[17] J.-Y. Zhou, J. Chen, S.-W. Zhou, and Z.-X. Mo, "Individual and combined effects of rhynchophylline and ketamine on proliferation, NMDAR1 and GluA2/3 protein expression in PC12 cells," Fitoterapia, vol. 85, no. 1, pp. 125-129, 2013. 
[18] L. Bo, Z. Baosheng, L. Yang et al., "Herb-drug enzymemediated interactions and the associated experimental methods: a review," Journal of Traditional Chinese Medicine, vol. 36, no. 3, pp. 392-408, 2016.

[19] I.-S. Song, T. Y. Kong, H.-U. Jeong et al., "Evaluation of the transporter-mediated herb-drug interaction potential of DA9801, a standardized dioscorea extract for diabetic neuropathy, in human in vitro and rat in vivo," BMC Complementary and Alternative Medicine, vol. 14, article no. 251, 2014.

[20] Y. Hijazi and R. Boulieu, "Contribution of CYP3A4, CYP2B6, and CYP2C9 isoforms to N-demethylation of ketamine in human liver microsomes," Drug Metabolism and Disposition, vol. 30, no. 7, pp. 853-858, 2002.

[21] S.-Z. Chen, P.-P. Pan, S.-H. Wang et al., "In vitro and in vivo drug-drug interaction of losartan and glimepiride in rats and its possible mechanism," Pharmacology, vol. 95, no. 3-4, pp. 133138, 2015.

[22] J. Z. Cai, C. L. Lin, L. F. Hu, G. Y. Lin, X. Q. Wang, and J. S. $\mathrm{Ma}$, "Determination of Isocorynoxeine in Rat Plasma by Liquid Chromatography Mass Spectrometry and Its Application," Journal of Liquid Chromatography \& Related Technologies, vol. 36, no. 16, pp. 2232-2241, 2013.

[23] J. Ma, J. Cai, G. Lin et al., "Development of LC-MS determination method and back-propagation ANN pharmacokinetic model of corynoxeine in rat," Journal of Chromatography B, vol. 959, pp. 10-15, 2014.

[24] J.-T. Chen and R.-M. Chen, "Mechanisms of ketamine-involved regulation of cytochrome P450 gene expression," Expert Opinion on Drug Metabolism \& Toxicology, vol. 6, no. 3, pp. 273-281, 2010.

[25] A. Meneguz, S. Fortuna, P. Lorenzini, and M. T. Volpe, "Influence of urethane and ketamine on rat hepatic cytochrome $\mathrm{P} 450$ in vivo," Experimental and Toxicologic Pathology, vol. 51, no. 4-5, pp. 392-396, 1999.

[26] W. Wang, C.-M. Ma, and M. Hattori, "Metabolism and pharmacokinetics of rhynchophylline in rats," Biological \& Pharmaceutical Bulletin, vol. 33, no. 4, pp. 669-676, 2010. 

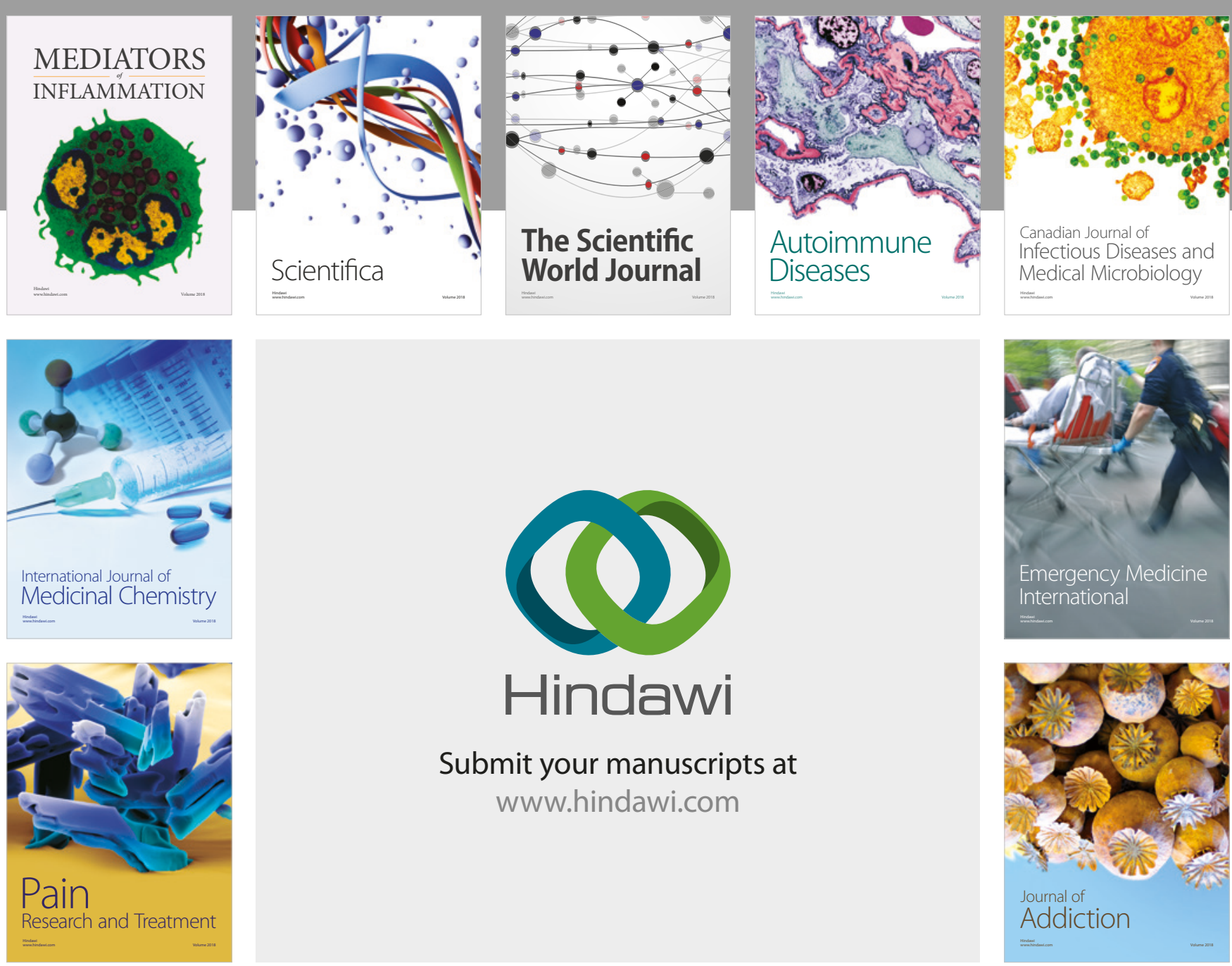

Canadian Journal of
Infectious Diseases and Medical Microbiology

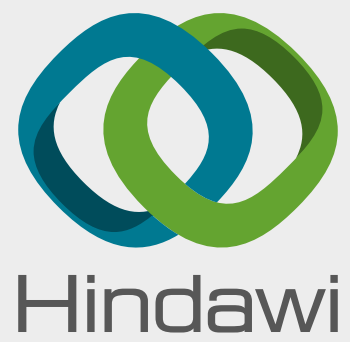

Submit your manuscripts at

www.hindawi.com
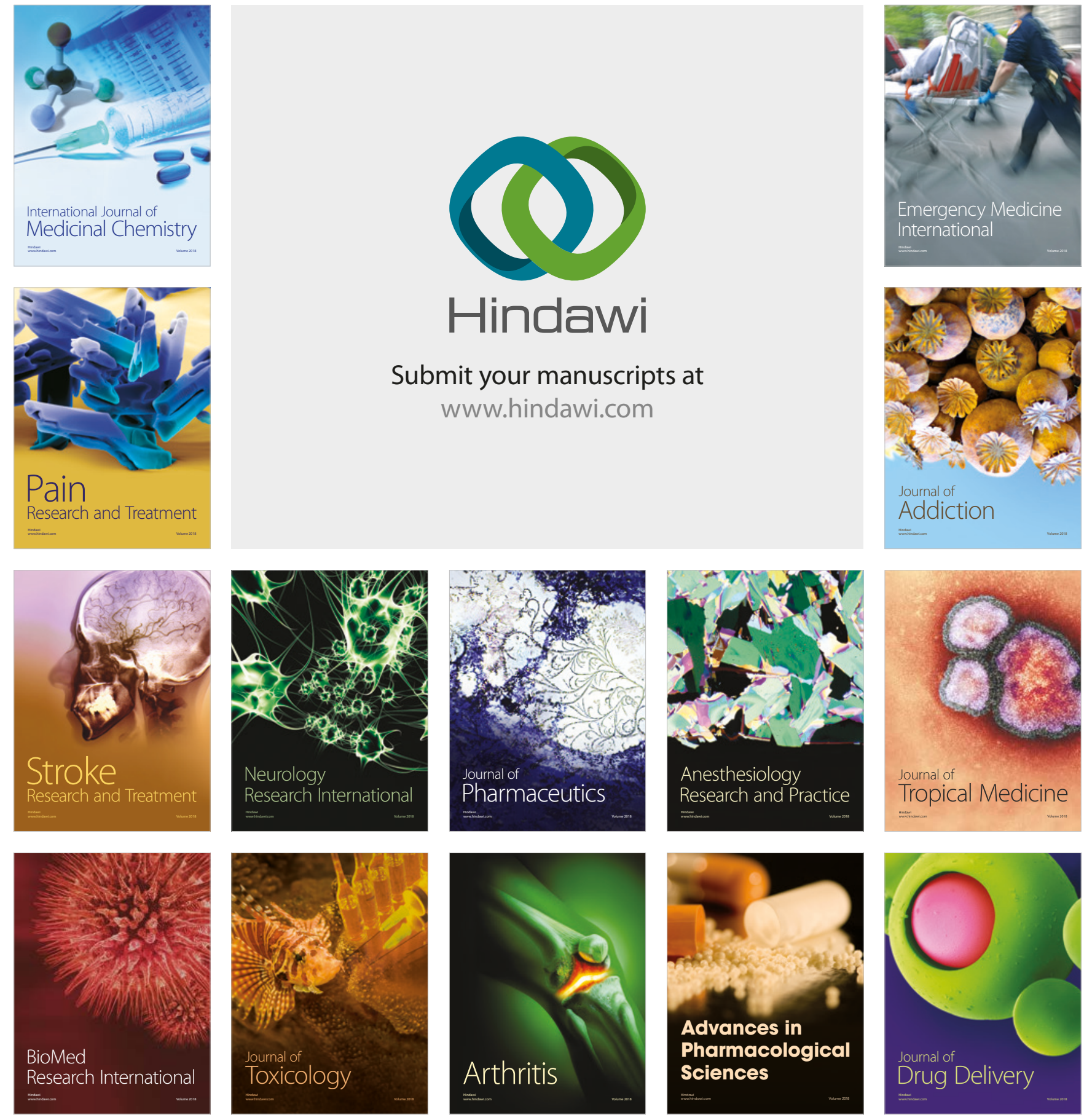